\title{
PSYCHE.
}

\section{ON THE NERVOUS SYSTEM OF THE HEAD OF THE LARVA OF CORYDALUS CORNUTUS LINN.}

BY WILLIAM CHRISTOPHER KRAUSS, ATTICA, N.Y.

[With Plate 2.]

[Extract from a thesis in entomology, presented to the Faculty of the Cornell university for the Baccalaureate in science.]

The nervous system of the head of the larva of Corydalus cornutus Linn., consists of -

I. The supra-oesophageal ganglia or cerebrum, and nerves.

2. The crura cerebri.

3. The sub-oesophageal ganglion or cerebellum, and nerves.

4. The commissures.

5. The vagus nerve.

I. The supra-oesophageal GaNglia, or CEREBrum. - The supra-oesophageal ganglia (fig. I. I) are situated in the dorso-cephalad part of the head, midway between the tips of the labrum and the base of. the head. They lie dorsad of the oesophagus, and immediately entad of the dorsal body wall, being separated from it only by thin, delicate layers of adipose tissue.

The supra-oesophageal ganglia, the probable homologs of the vertebrate cerebrum, differ greatly from the other ganglia or nerve centres of the body. They are a compound organ composed of two distinct ganglia or hemispheres connected together by a short, thick commissure on the meson, but are sometimes described as a single ganglion. These hemispheres are similar in outline, having an ovoid appearance. The lateral ends of the hemispheres taper into the cerebral nerves. In the twoyear-old larva, the cephalo-caudal diameter of the hemispheres is three-fourths of a millimetre, and the two together attain the length of two millimetres.

The ventro-latero-cephalad borders of the cerebrum are developed ventrad, forming the crura cerebri, which connect it with the sub-oesophageal ganglion.

The cephalad extremity of the aorta is attached to the neurilemma, at the cau- 
dad border of the supra-oesophageal ganglia on the meson. The opening of the aorta appears as is shown in the plate, fig. I. 7, the dorsal wall having a forked opening near the attachment of the aorta to the neurilemma.

The supra-oesophageal ganglia are supplied by two large tracheae lying parallel to the oesophagus (fig. IV, 4). Each trachea sends three branches to the ventral side of each hemisphere. These branches divide and sub-divide, ramifying to all parts of the hemispheres (fig. IV). The supra-oesophageal ganglia are covered with a thin, delicate curtain-membrane, the neurilemma.

The cerebral nerves. - The cerebral nerves consist of two trunks of nerves, which originate from two tracts at the lateral apices of the supra-oesophageal ganglia. The cephalad tract gives rise to the antennal nerve, and also a small integumentary nerve, and may therefore be called the antennal tract. The caudad tract gives rise to the optic nerves, and may therefore be called the optic tract.

The antennal nerve. - The antennal nerve (fig. I. 4) arises from the antennal tract. It extends laterad a distance of one and one-half millimetres, and divides into a cephalad and a caudad branch.

The cephalad branch (fig. I. 4. a) continues its course laterad, then cephalad, and enters the antenna, supplying it with nerves. It is therefore, probably, the tactile or sensor nerve of the antenna.

The caudad branch (fig. I. 4. b) con- tinues laterad, and enters the muscles of the antenna in the head (fig. r. 9). At the point of entering the muscles it divides into several small branches. This nerve is probably the motor nerve of the antenna. Another small nerve (fig. I. 4. c) arises from the antennal tract, and extends laterad a distance of two millimetres ; it then divides into two branches. These branches pass dorsad of the antennal muscles, and enter the integument near the retinas of the eyes.

The optic norves. - The optic trunk of nerves (fig. I. 5) arises from the optic tract. This trunk extends laterad a short distance and divides into seven distinct branches, the optic nerves. These branches continue their course laterad, and are distributed one to each of the seven retinas. It is an interesting fact, that although there are seven retinas, the external parts of only six ocelli are developed. The presence of the seventh retina and optic nerve cannot be doubted, as it was observed in many specimens of the one- and twoyear-old larvae. Fig. vi shows the separation of the optic trunk into the seven optic nerves. The optic and antennal nerves are protected by a covering, the extension of the neurilemma or theca (fig. vi. 3) which covers the sub- and supra-oesophageal ganglia and nerves.

2. The crura cerebri. - The crura cerebri or the cerebro-cerebellar commissures (fig. IV. 3 and fig. VII. 2) are two cords of nerve matter connecting the sub- and supra-oesophageal ganglia, and with them encircle the oesophagus. 
They arise from the ventro-latero-cephalad portions of the supra-oesophageal ganglia, and extend ventrad, joining the sub-oesophageal ganglion at its dorsolatero-cephalad borders. They are similar in outline and appearance to the commissures of the body. They present a convexity laterad and a concavity mesad, corresponding to the cylindrical outline of the oesophagus.

The crural nerves. - At the points. of departure of the crura cerebri from the supra-oesophageal ganglia, each crus gives off two nerves, the vagus and the clypeo-labral (fig. I. 2, 3 and fig. Iv. 8, 9). The vagus nerve will be described later as a special part of the nervous system of the head.

The clypeo-labral nerves.-The clypeo-labral nerves, two in number, arise one from each crus near its origin (fig. I. 3). They extend cephalad and a little mesad. Each gives off three small branches in the clypeus, and a fourth, long branch which extends cephalad to the base of the labrum and penetrates the integument. After giving off these branches, the main trunk extends cephalad into the labrum and may be termed the labral nerve. This labral nerve divides into several small branches near the tip of the labrum. The largest of these branches enters a labral palpus (?), or probably a seta.

The crura cerebri are joined together by a cord of nerve matter (fig. vir. 3 ) one-half millimetre from their attachments to the sub-oesophageal ganglion. This cord or cross-nerve of the commissures is dorsad of the cephalad part of the sub-oesophageal ganglion, and is entirely concealed by it. The crossnerve arises from the commissures and like the commissures follows the outline of the oesophagus, presenting a convexity ventrad, and a concavity dorsad.

3. The sub-oesophageal GanGLION, OR CEREBELLUM. - The sub-oesophageal ganglion (fig. II. I) is situated in the ventro-cephalad part of the head, midway between the tips of the labium and the base of the head. It lies ventrad of the oesophagus, and is separated from the ventral body-wall by a layer of muscles and by adipose tissue. The sub-oesophageal ganglion, the probable homolog of the vertebrate cerebellum, differs somewhat from the other ganglia. It is nearly cordate in outline, with two apices pointing caudad and terminating in the commissures. Its cephalo-caudal diameter is one and onehalf millimetres, and its greatest width is one millimetre, in the two-year-old larva. It is connected to the supra-oesophageal ganglia by the crura cerebri, and to the other ganglia of the body by the commissures. It is covered with a thin, delicate curtain-membrane, the neurilemma.

Tracheae also penetrate the body of the ganglion, ramifying to all parts.

The cerebellar nerves. - The cerebellar nerves consist of a pair each of labial, gustatory, maxillary, and mandibular nerves, and three other, unnamed pairs of nerves.

The labial nerves. - The labial nerves (fig. Ir. 3) originate from the ventro-latero-cephalad borders of the sub- 
oesophageal ganglion, and continue their course cephalad into the labium. At a point one millimetre from the ganglion two branches are given off laterad, one from each nerve, which divide into several small branches piercing the integument.

At a point two millimetres from the ganglion two branches are given off, one from each nerve, going cephalolaterad to the integument.

At a point three millimetres from the ganglion the labial nerve separates into two large branches, one extending to the palpus, and one to the distal end of the ligula. The nerve of the labial palpus enters that organ, and near its extremity separates into several small branches. The ligular nerve continues cephalad into the ligula, and near its extremity divides into two or three small branches. The nerve of the labial palpus gives off a very small nerve at the point of entering the palpus.

The gustatory nerves. - The gustatory nerves (fig. II. 2), if they may be so called, arise from the cephalad border of the sub-oesophageal ganglion, and continue their course cephalad into the ligula, being in close relation to the floor of the mouth. At a point three millimetres from the ganglion, at the caudad part of the ligula, the nerves meet on the meson, forming an arch. The dextral nerve sends a small nerve laterad about one and one-half millimetres from the ganglion, while the sinistral nerve sends a branch laterad one millimetre from the ganglion. The two nerves, at the point of changing their course from cephalad to mesad, give off two branches, one from each nerve. These branches continue cephalo-laterad, piercing the floor of the mouth. These branches also divide into several smaller branches. The arch of the gustatory nerves gives off two small nerves, going cephalad, which unite at a point one millimetre from the arch. This united nerve divides into three small nerves, one going cephalad, and two going cephalo-laterad. The gustatory nerves and branches are very fine and delicate, and are closely related to the integument which forms the walls of the labium and ligula.

The maxillary nerves, - The maxillary nerves (fig. II. 5 and fig. III) arise from the ventro-latero-cephalad borders of the sub-oesophageal ganglion as a single trunk, which immediately divides into four branches. These may be indicated by the letters a, b, c, d, fig. Ir. 5 , and $\mathrm{A}, \mathrm{B}, \mathrm{C}$, fig. III.

Nerve A (fig. III), which is the largest of the branches, forks at a point about two millimetres from the ganglion. Both branches enter the maxilla, going to its extremity, and one of them enters the maxillary palpus.

Nerve 13. - This branch divides into two branches, three millimetres from the ganglion, one branch forking immediately and going cephaliad. The other branch continues laterad, divicing into several branches which pierce the integument.

Nerve c. - This branch forks two millimetres from the ganglion, one branch going cephalad to the maxilla, the other 
branch going caudad, giving branches to the maxillary muscles in the head. The cephalad branch divides into two branches four and one-half millimetres from the ganglion, both continuing their course cephalad.

The fourth nerve (fig. Ir. 5. $d$ ) is a very small nerve which divides into two branches entering the maxillary muscles.

The mandibular nerve. - The mandibular nerve (fig. II. 4 and fig. v) arises from the dorso-latero-cephalad borders of the sub-oesophageal ganglion, and continues laterad to the mandibles. Before entering the mandibles three branches are given off (fig. v. 2, 3, 4).

The first branch (fig. v. 2) gives off two nerves which go caudad, entering the mandibular muscles.

The second branch (fig. v. 3) goes laterad a short distance, then forks. The caudad fork, dividing into two branches, enters the mandibular muscles. The cephalad branch is united to a long nerve going cephalad. This nerve forks one and one-half millimetres from the base of the mandibles. This nerve extends caudad of its attachment to nerve 3 (fig. v), and enters a muscle. Just caudad of its attachment to nerve 3 it gives off a very fine and delicate nerve which goes cephalad into the mandibles. Nerve 4 (fig. v) goes laterad two millimetres, then forks, one branch going caudad to supply the mandibular muscles in the head, the other branch going cephalad into the mandibles. The mandibular nerve gives off a branch at the point of entering the mandibles, two branches one and one-fourth millimetres from the base of the mandibles, and then forks at a point two and one-fourth millimetres from the base into two branches, which continue their course cephalad. The more minute branches of the mandibular nerve are shown in fig. $\mathrm{v}$.

Other nerves. - A small nerve (fig. II. 6) arises immediately caudad of the attachment of the labial nerve on the ganglion, and divides into several branches going to the adjacent muscles.

From the lateral borders of the suboesophageal ganglion two nerves are given off, one on each side, going caudad parallel to the commissures (fig. II. 8). These nerves enter the perivisceral cavity.

At the caudad part of the ligula, three millimetres from the sub-oesophageal ganglion on the meson, are attached two long nerves going caudad (fig. II. 7). These nerves are joined to the labial nerves by neurilemma and by two very fine nerves, one on each side. At the ganglion each nerve gives off two small, delicate nerves which are joined to nerve 6 (fig. II). The main branch continues caudad, but no caudal attachment was found. The cephalad attachment of these nerves is not shown in fig. II, having been dissected away to show the cephalad extremity of the gustatory nerves.

4. The commissures. - The caudad end of the sub-oesophageal ganglion terminates in two large white cords, the commissures (fig. II. 9, fig. vir. 4). These commissures are similar to the commissures of the body, and join the sub-oesophageal ganglion to the first 
thoracic. Each commissure gives off a nerve three and one-half millimetres from the ganglion, going caudad. The distance of these nerves from the ganglion varies however (fig. II. 0 ).

5. The vagus nerve. - The vagus nerve of Corydalus cornutus arises as two nerves from the crura cerebri, dorsad of the labial nerves (fig. IV. 9). These nerves pass cephalo-mesad, forming two arches, and unite in a ganglion on the median line dorsad of the palate. This ganglion (fig. I. 2, fig. IV. 2) is sometimes called the frontal ganglion, and is immediately cephalad of the supra-oesophageal ganglion. The vagus nerve departs from the caudad part of the ganglion, passes caudad between the aorta and the oesophagus, and continues on the median line until it reaches a point two millimetres caudad of the frontal ganglion (fig. IV. 9). Here it enters another ganglion smaller than the frontal ganglion. This ganglion is also situated on the median line between the aorta and the oesophagus. Two nerves depart from this ganglion, going laterocaudad to the sides of the oesophagus (fig. I. 8, fig. IV. o). They continue their course caudad until they reach the pro-ventriculus, where they divide into many branches.

The vagus nerve gives branches to the aorta in the head, and numerous nerves are continually given off to the oesophagus.

\section{SEXUAL CHARACTERS IN THE CHRYSALIDS OF GRAPTA INTERROGATIONIS.}

BY MARY ESTHER MURTFELDT, KIRKWOOD, MO.

The publication in Psyche for November-December I883, v. 4, p. Iо3Io6, of the full text of Mr. Lintner's interesting paper on "A new sexual character in the pupae of some lepidoptera," reminds me of an observation which I made last summer on the chrysalids of Grapta interrogationis.

Desirous of obtaining fresh specimens of this species, I placed about a dozen clm-feeding larvae in a rearing cage, from which, in due time, I sbtained eleven chrysalids. These were, in respect to color and ornamentation, of two distinct sorts. The larger proportion were of a dull, pale fuscous with darker brown lateral stripes, dots and markings, without a trace of metallic ornamentation, while four were much paler in general color, inclining to golden brown, each ornamented with the eight brilliant, pale-golden, papillose dorsal spots by which this chrysalis is usually characterized. From each of the pale and gilded chrysalids emerged a female, while the seven dark and unornamented ones gave forth males exclusively. This observation may be a mere corroboration of a well known fact concerning the sexual characters of the species, but if so I have not met with it, or it has entirely escaped my memory. 


\section{Explanation of Plate 2.}

Fig. I. Dorsal view of the head, showing the supra-oesophageal ganglia and nerves. $\times 6$.

I, Supra-oesophageal ganglia. 2, Frontal ganglion. 3, Clypeo-labral nerve. 4 , Antennal nerve. $a$, Sensor branch. $b$, Motor branch. $c$, Integumentary branch. 5, Optic nerves. 6, Oesophagus. 7, Aorta. 8, Vagus nerve. 9, Antennal muscles.

Fig. II. Ventral view of the head, showing the sub-oesophageal ganglion and nerves. $\times 6$.

I, Sub-oesophageal ganglion. 2, Gustatory nerve. 3, Labial nerve. 4, Mandibular nerve. 5, Maxillary nerve. 6, 7,8, Unnamed nerves. 9, Commissure. o, Commissural nerve.

Fig. III. The maxilla with its three large nerves. Nerve $d$, fig. II, not shown. $\times 7$.

Fig. IV. Ventral aspect of the supra-oesophageal ganglia, the crura cerebri turned cephalad. $\times 15$.

I, Supra-oesophageal ganglia. 2, Frontal ganglion. 3, Crura cerebri. 4, Tracheae. 5, Aorta. 6, Optic nerves. 7, Antennal nerve. 8, Clypeo-labral nerve. 9, Vagus nerve. o, Vagus nerve.

Fig. v. The mandible with its nerves. $\times 7$.

Fig. vi. The separation and dissection of the seven optic nerves. $\times$ Io. I, Optic trunk of nerves. 2, Optic nerve. 3, Neurilemma.

Fig. vil. Showing principally the cross-nerve of the crura cerebri, the cephalad extremity of the sub-oesophageal ganglion having been dissected away. $\times$ I 2 .

I, The sub-oesophageal ganglion. 2, Crura cerebri. 3, Cross nerve. 4, Commissure. 

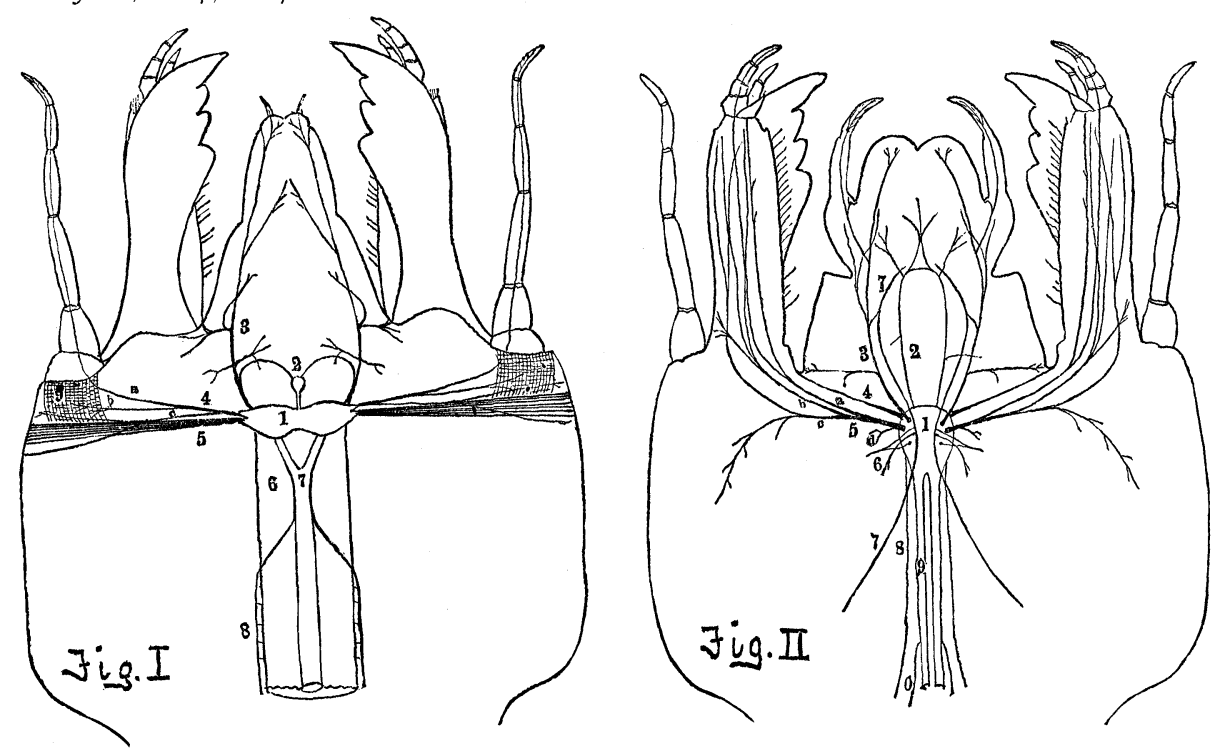

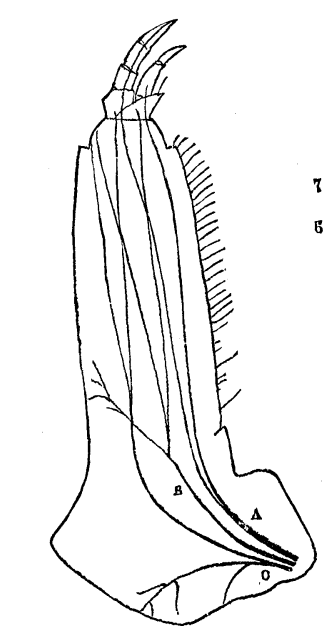

Jio. II
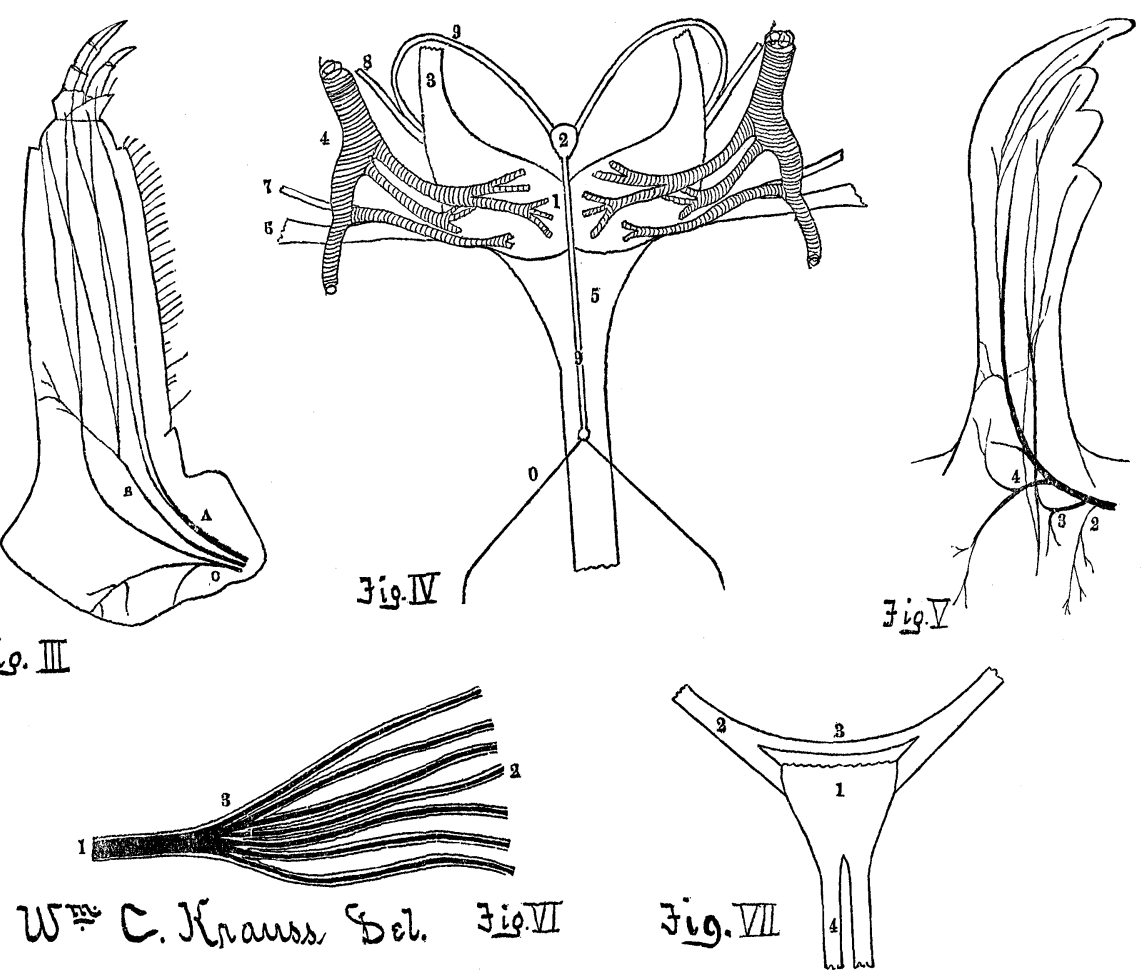

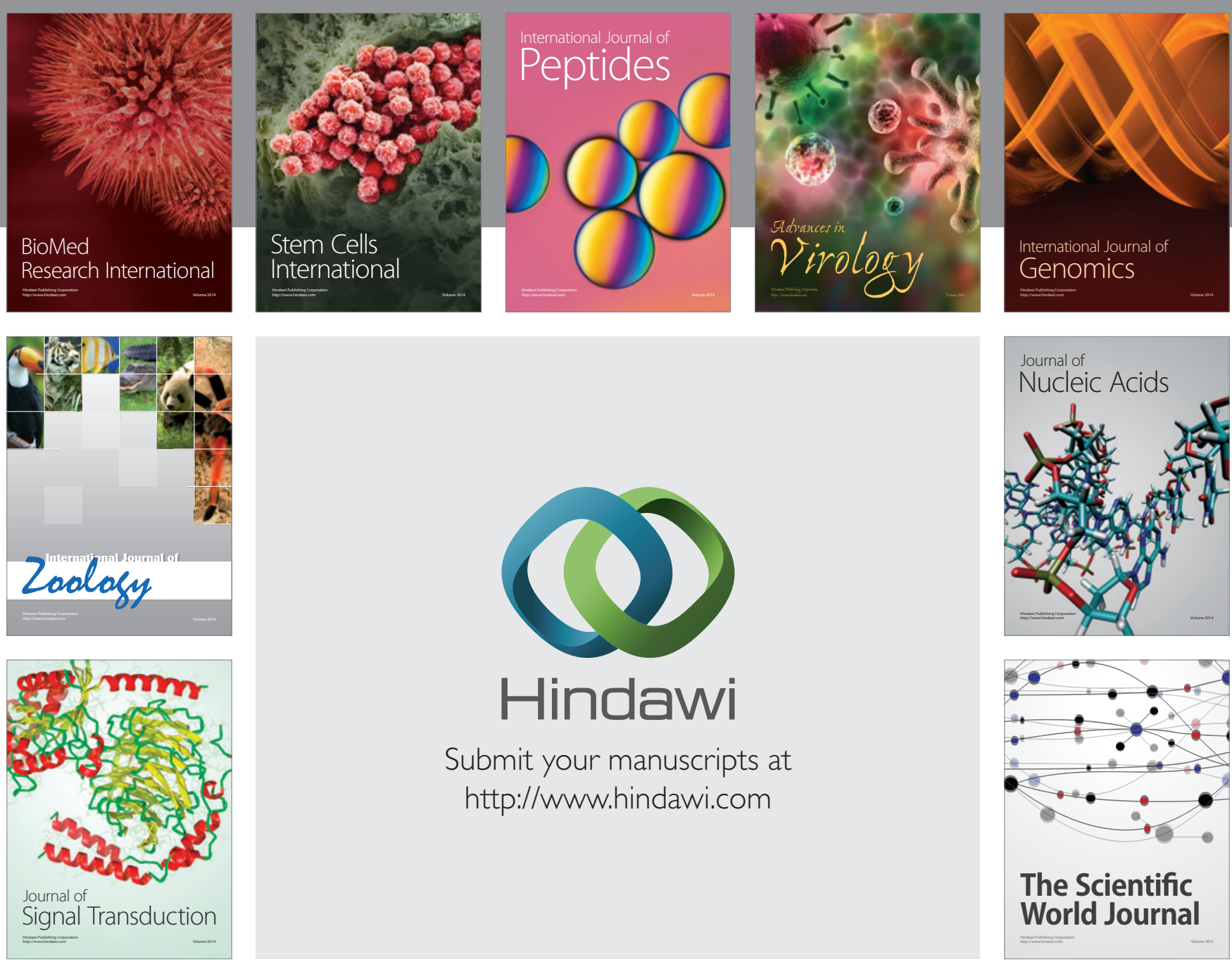

Submit your manuscripts at

http://www.hindawi.com
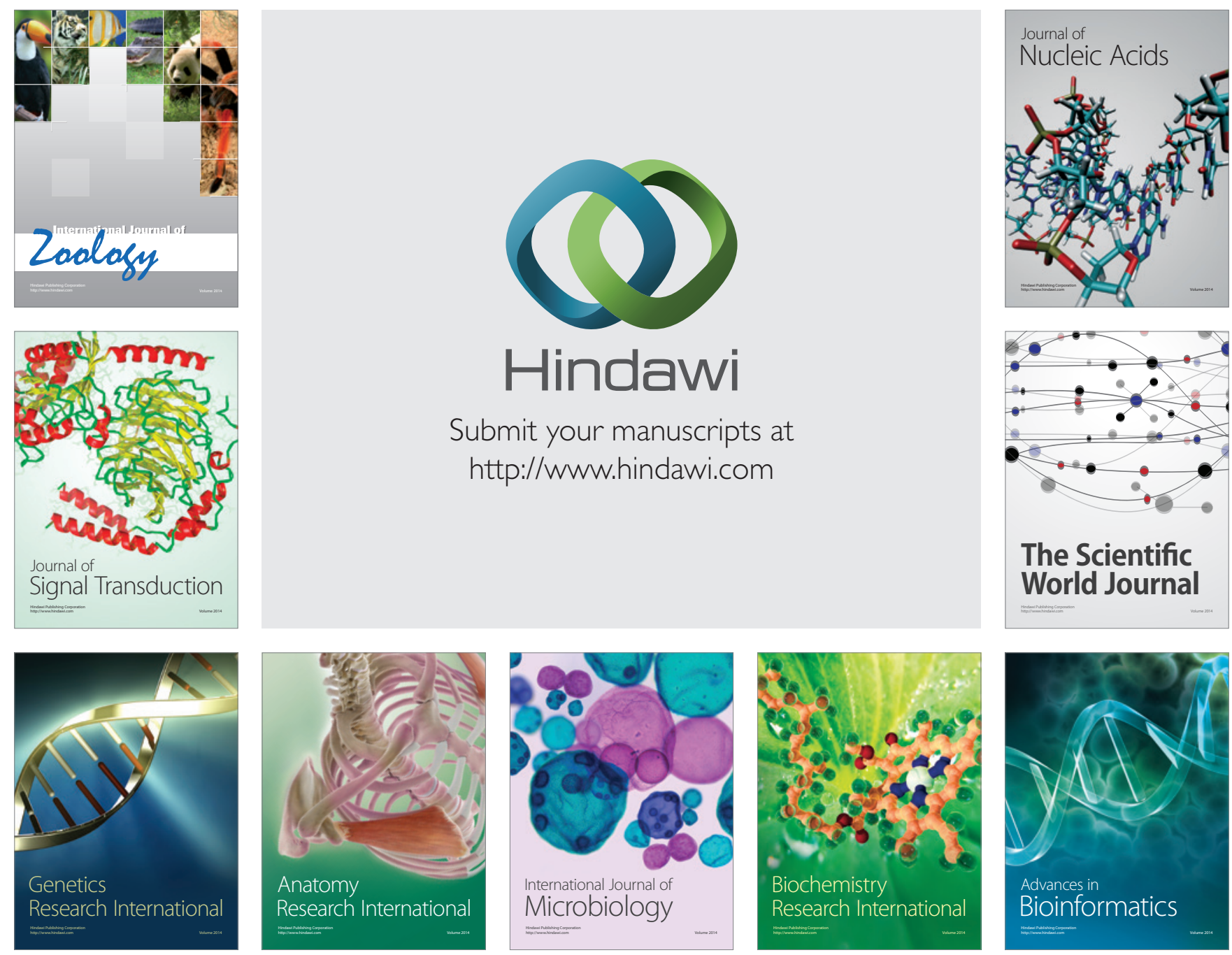

The Scientific World Journal
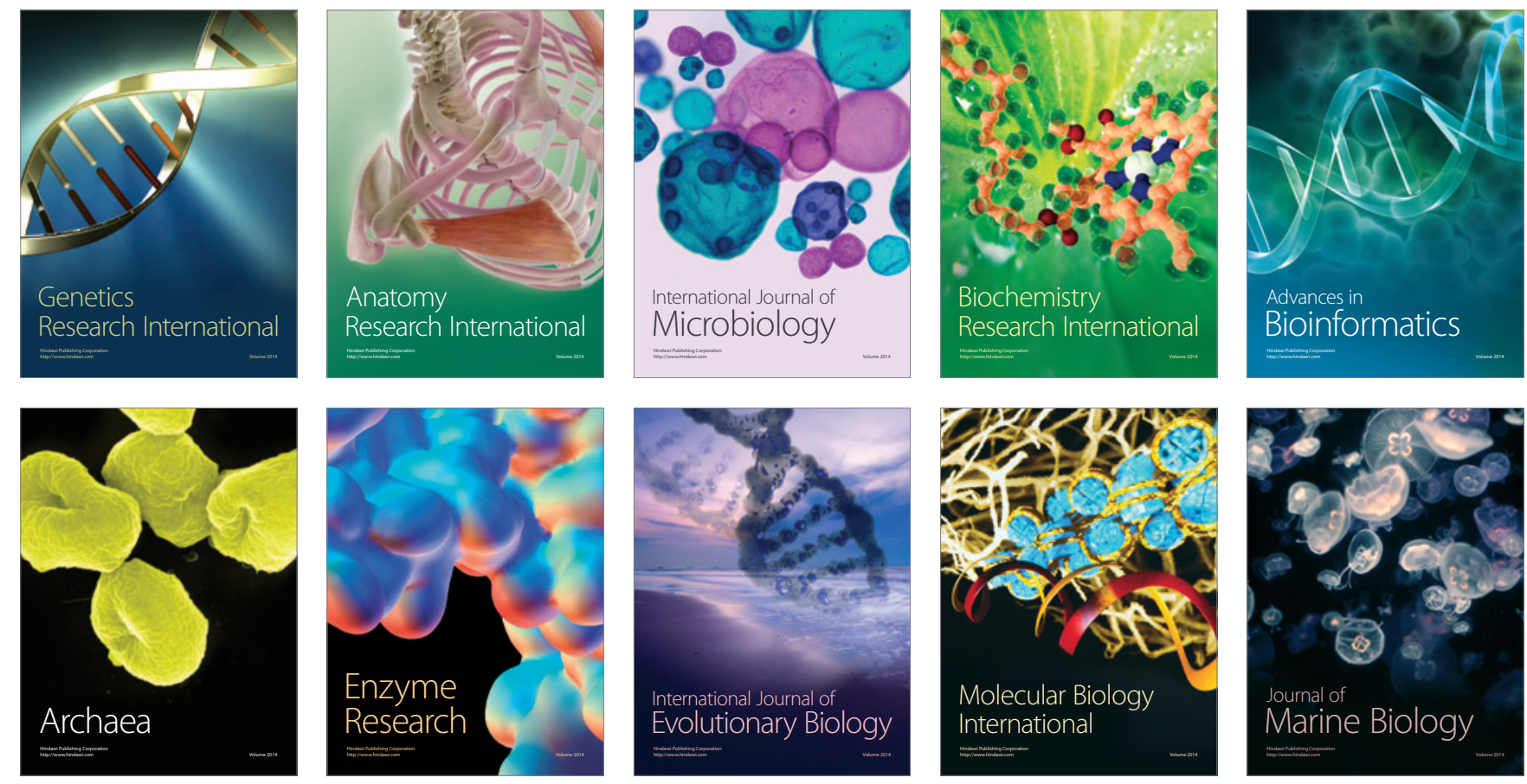